\title{
Análise Multicritério aplicada ao mapeamento de risco de incêndio na APA Sul RMBH
}

\section{Multicriteria analysis applied to fire risk mapping at APA Sul RMBH}

\author{
Felipe Fernandes Ladislau \\ Geógrafo, Mestrando em Geografia Aplicada e Geotecnologias, UFMG \\ Especialista em Geoprocessamento e Análise Espacial, PUC Minas \\ Bolsista do Conselho Nacional de Desenvolvimento Científico e Tecnológico (CNPq), Brasil \\ felipe.fernandesladislau@live.com
}

Jaqueline da Consolação Silva

Geógrafa, Mestranda em Geografia e Análise Ambiental, UFMG

Bolsista da Coordenação de Aperfeiçoamento de Pessoal de Nível Superior (CAPES), Brasil

jaquellinesilva94@gmail.com

Ana Paula Minelli Moreira

Geógrafa, Mestranda em Geografia e Análise Ambiental, UFMG

Bolsista da Coordenação de Aperfeiçoamento de Pessoal de Nível Superior (CAPES), Brasil

anapaulaminelli18@,gmail.com

Gabriel Luca Nascimento

Geólogo, Mestrando em Geografia e Análise Ambiental, UFMG

Bolsista da Coordenação de Aperfeiçoamento de Pessoal de Nível Superior (CAPES), Brasil

gabrielluca.geo@gmail.com

Úrsula de Azevedo Ruchkys

Geóloga, Doutora em Geologia, UFMG

Professora do Departamento de Cartografia e do Programa de Pós-Graduação em Análise e Modelagem de Sistemas Ambientais, UFMG, Brasil

tularuchkys@yahoo.com.br

\begin{abstract}
Resumo
Queimadas são uma ameaça a conservação dos ecossistemas em especial em Unidades de Conservação, territórios de grande valor considerando seus atributos físicos e bióticos, podendo resultar em impactos significativos e duradouros tanto do ponto de vista ecológico, como social e econômico. O objetivo deste trabalho foi realizar um mapeamento de áreas susceptíveis a risco de incêndio na APA Sul RMBH com uso de técnicas de geoprocessamento. Foi utilizada a análise multicritérios pelo modelo de Análise Hierárquica de Processos (AHP) considerando dados secundários referentes às características fisiográficas e socioeconômicas da área de estudo. O mapa resultante, com as áreas de maior risco a ocorrência de incêndios, indicou predominância de risco médio ao longo da APA Sul, sendo que as áreas de alto risco concentraram-se em locais com as menores cotas altimétricas do recorte, declividades mais planas, em locais de pastagem e mosaicos de agricultura, regimes de precipitação e temperatura intermediários, enquanto que as áreas menos propícias a incêndios localizaram-se em locais de afloramento rochoso, elevada altimetria, declividade montanhosa a escarpada e afastadas das principais localidades e rodo-ferrovias. Acreditase que o uso de geotecnologias para esse fim possa subsidiar no planejamento e gestão desta importante unidade de conservação
\end{abstract}

Palavras-chave: risco de incêndio, análise multicritério, análise hierárquica de processos, APA Sul RMBH 


\begin{abstract}
Burns are a threat to the conservation of ecosystems, especially in Conservation Units, territories of great value considering their physical and biotic attributes, which can result in significant and lasting impacts from an ecological and a social and economic point of view. The objective of this work was to map areas susceptible to fire risk in APA Sul RMBH using geoprocessing techniques. Multicriteria analysis was used by the Hierarchical Process Analysis (AHP) model considering secondary data regarding the physiographic and socioeconomic characteristics of the study area. The resulting map, with the areas with the highest risk of fire occurrence, indicated a predominance of medium risk throughout the APA Sul, with the high-risk areas concentrated in places with the lowest elevations in the cutout, flatter slopes, in pastures and agricultural mosaics, intermediate precipitation and temperature regimes. In contrast, areas less prone to fires are located in rocky outcrops, high altimetry, mountainous to steep slopes and away from the main localities and roadways. It is believed that the use of geotechnologies for this purpose can subsidize the planning and management of this important conservation unit
\end{abstract}

Keywords: fire risk, multicriteria analysis, hierarchical process analysis, APA Sul RMBH.

\title{
1. INTRODUÇÃO
}

As expectativas em relação à gestão de unidades de conservação aumentaram nos últimos anos e incluem uma série de preocupações relativas à importância dessas áreas para o fornecimento se serviços ecossistêmicos, como habitat para espécies ameaçadas, água potável, estoque de carbono e oportunidades cênicas e recreativas. As queimadas nessas áreas apresentam um grande desafio para o setor público, provocando impactos na captação de água, alterações no solo e diminuição da fauna e flora nativa (IEF, 2020). Sabe-se que as queimadas podem ser de origem natural ou antropogênica, assim como há fatores que influenciam na proporção da propagação do fogo, como o uso do solo, proximidade de áreas urbanas, condições do tempo meteorológico e relevo.

Para diminuir os efeitos gerados pela ação do fogo é necessário, além de um bom sistema de gestão de combate, identificar áreas mais susceptíveis ao risco de incêndio, o que pode representar uma estratégia de prevenção e direcionamento de recursos com boa relação custo-benefício.

Considerando que diferentes fatores podem contribuir para o maior risco de incêndios, é imprescindível a análise do ambiente de forma a contemplar os fatores mais significativos que possam iniciar e potencializar as queimadas.

A partir da identificação destes atores socioambientais que interferem nos efeitos da combustão, é possível analisar, explorar e comparar os níveis de ação destes com o uso de Sistemas de Informações Geográficas (SIG). O uso de SIG permite mapear as zonas potenciais de risco de incêndio tornando as ações de combate e prevenção mais efetivas, uma vez que há possibilidade de manejar os esforços de acordo com as demandas de cada áreas. Sobre os mapas de risco de incêndio Silva (2004) explica que: 
(...) é o resultado da sobreposição dos vários mapas temáticos desenvolvidos para este fim. $\mathrm{Na}$ verdade, o mapa não consiste da simples superposição dos mapas, mas delimitação de áreas de acordo com o nível de risco em função da somatória ponderada dos riscos parciais de cada variável analisada (SILVA, 2004, p.10).

O uso de SIG é utilizado por alguns autores para auxiliar no mapeamento de risco de incêndios, com destaque para Silva (2004), Vetorazzi (2006), Nery (2011), Lazzarin et al (2015), Torres et al (2017), Fernandes et al (2020).

Silva (2004) analisou o grau de ocorrência de incêndios florestais no Parque Estadual do Itacolomi através de modelo de ponderação multicritério sobre variáveis de cobertura vegetal, proximidade a áreas urbanas, proximidade a estradas e a declividade do terreno. A categorização das classes de informação, bem com a atribuição de notas, fora realizada com base em revisão conceitual sobre predisposição à ocorrência dos incêndios, numa variação entre o risco mais baixo ao mais elevado. A ponderação final deu-se através de uma equação que teve como resultado o somatório entre as variáveis analisadas.

Vettorazzi (2006) identificou áreas prioritárias para restauração florestal visando a conservação de recursos hídricos, tendo como recorte a bacia hidrográfica do Rio Corumbataí. O autor utilizou bases de uso e cobertura do solo, solos, classes de capacidade de uso da terra e classes de declividade, níveis de erodibilidade do solo, erosividade pela chuva, rede hidrográfica e malha viária. Para ponderação das variáveis analisadas, foi utilizado o modelo de Técnica participatória, proposto por Saaty (1977), junto da matriz de comparação pareada. A definição dos pesos, além de ter como base a avaliação de especialistas. A ponderação final foi implementada através da matriz de comparação, em escalas de importância que variaram entre 1/9 - o que caracteriza menor importância absoluta - a 9, grau de importância total, intercalados em valores ímpares. Como resultado final, obteve-se o mapa de áreas prioritárias para conservação.

Nery (2011) mapeou as áreas potenciais para risco de incêndio no Parque Estadual da Serra da Canastra através do modelo de análise AHP. As variáveis analisadas foram sub-categorizadas em elementos fisiográficos (uso do solo e declividade) e fatores de ignição, que propiciam a formação de incêndios (proximidade a estradas, proximidade a trilhas, focos de calor e proximidade a atrativos turísticos). As variáveis e suas classes foram analisadas e ponderadas por consulta a especialistas e da matriz de comparação de processos, tendo como produto final o mapa de risco objetivado.

Lazzarin et al (2015) analisaram a ocorrência de incêndios em áreas eminentemente urbanas e sua detecção por sensores remotos. Dados de focos de calor foram cruzados com dados de ocorrências de incêndios registradas em campo e combatidas por grupamentos de alguns municípios do estado do Tocantins designados para tanto. Torres et al (2017) definiram, por meio da análise de influência de fatores preditores como clima, relevo, uso do solo e influência antrópica, um mapa de risco de incêndios florestais com a utilização de técnicas de geoprocessamento. 
Por fim, Fernandes et al (2020) utilizaram de imagens Modis (MCD45A1) para identificação e avaliação de áreas queimadas na região metropolitana de Belo Horizonte, entre os anos de 2012 e 2016, validando-as com dados do sensor Landsat-8/OLI. C

Considerando a discussão apresentada, este artigo tem como objetivo mapear o risco de incêndio na APA Sul RMBH, utilizando análise multicritério, com o modelo de ponderação (AHP Análise Hierárquica de Processos) em ambiente SIG a fim de fornecer instrumentos para a previsão e/ou controle dos focos de fogo na região.

\section{CARACTERIZAÇÃo DA ÁREA DE ESTUdO}

A área ocupada pela APA Sul possui uma extensão de 1.632,5 km², estando localizada na porção sul da região metropolitana de Belo Horizonte (RMBH). A APA engloba 13 municípios, que integram não apenas a RMBH, como também seu colar metropolitano (tabela 1).

Tabela 1 - Dados populacionais e territoriais dos municípios ocupados pela APA Sul RMBH

\begin{tabular}{c|c|c|c|c|c|c}
\hline Município & População & $\begin{array}{c}\text { População } \\
\text { não } \\
\text { urbana }\end{array}$ & $\begin{array}{c}\text { População } \\
\text { urbana }\end{array}$ & $\begin{array}{c}\text { Área do } \\
\text { município } \\
\text { (há) }\end{array}$ & $\begin{array}{c}\text { Área da } \\
\text { UC no } \\
\text { município } \\
\text { (há) }\end{array}$ & $\begin{array}{c}\text { Área da } \\
\text { UC no } \\
\text { município } \\
\text { (\%) }\end{array}$ \\
\hline $\begin{array}{c}\text { Barão de } \\
\text { Cocais }\end{array}$ & 32.319 & 2.656 & 25.786 & $34.058,50$ & 339,66 & 0,21 \\
\hline Belo Horizonte & 2.501 .576 & 0 & 2.375 .151 & $33.140,10$ & $3.192,48$ & 1,94 \\
\hline Brumadinho & 39.520 & 5.330 & 28.643 & $63.943,40$ & $17.861,37$ & 10,84 \\
\hline Caeté & 44.377 & 5.314 & 35.436 & $54.253,10$ & $3.901,81$ & 2,37 \\
\hline Catas Altas & 5.330 & 606 & 4.240 & $24.004,20$ & $7.505,56$ & 4,56 \\
\hline Ibirité & 179.015 & 366 & 158.588 & $7.257,30$ & $1.758,96$ & 1,07 \\
\hline Itabirito & 51.281 & 1.882 & 43.567 & $54.260,90$ & $26.366,39$ & 16,01 \\
\hline Mário Campos & 15.207 & 733 & 12.459 & $3.519,60$ & $1.128,66$ & 0,69 \\
\hline Nova Lima & 93.577 & 1.766 & 79.232 & $42,900,40$ & $39.409,07$ & 23,93 \\
\hline Raposos & 16.277 & 790 & 14.552 & $7.222,80$ & $3.882,28$ & 2,36 \\
\hline Rio Acima & 10.203 & 1.146 & 7.944 & $22.981,20$ & $23.095,98$ & 14,02 \\
\hline Santa Bárbara & 30.807 & 3.083 & 24.793 & $68.406,0$ & $34.007,59$ & 20,65 \\
\hline Sarzedo & 32.069 & 281 & 25.533 & $6.213,40$ & $2.253,49$ & 1,37 \\
\hline
\end{tabular}

Fonte: os autores, com dados do Instituto Socioambiental - ISA (2021)

A APA Sul da RMBH foi criada pela lei $\mathrm{n}^{\mathrm{o}} 13.960$, de 26 de julho de 2001, que busca proteger os sistemas ambientais da RMBH, sendo uma UC na categoria de uso sustentável do Sistema Nacional de Unidades de Conservação (SNUC). A Instância de gestão da UC é estadual, cabendo a Secretaria de Estado de Meio Ambiente e Desenvolvimento Sustentável (SEMAD) as competências legais previstas. 


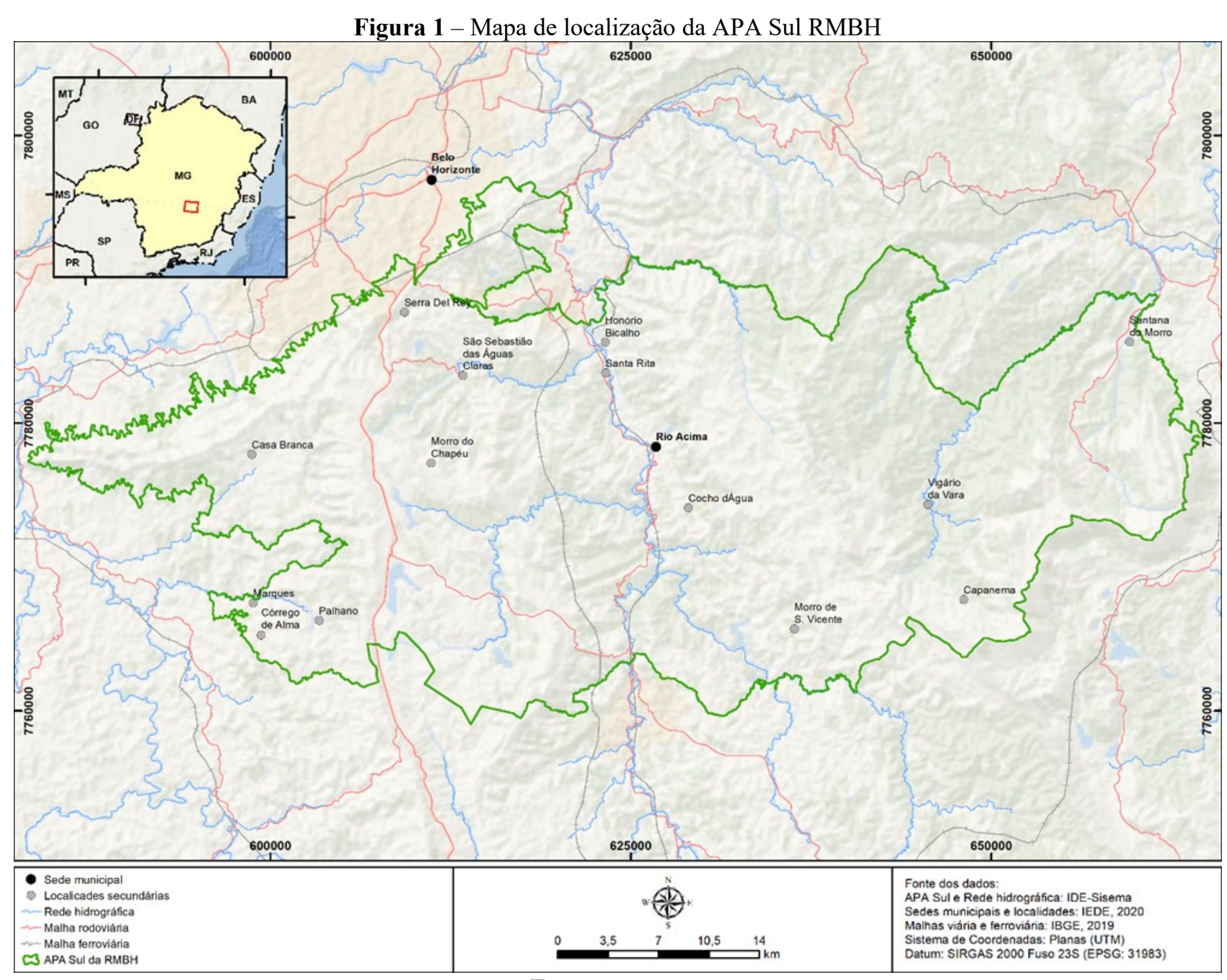

Fonte: os autores

Considerando o aspecto geológico, a APA Sul da RMBH está totalmente inserida no Quadrilátero Ferrífero (QFe). Representa uma região de grande importância econômica em nível mundial, devido às suas riquezas minerais, principalmente, ferro, ouro e manganês. O $\mathrm{QFe}$ se localiza na borda sul do Cráton São Francisco e é composto por rochas do Complexo Ortognáissico (complexos Belo Horizonte, Bonfim, Bação e Santa Bárbara) sotoposta pela sequência vulcanossedimentar do tipo greenstone belt arqueana (Supergrupo Rio das Velhas) e de cobertura plataformal proterozoica (Supergrupo Minas). As rochas fanerozoicas presentes na área são representadas por pequenas intrusões básicas, pequenos depósitos terciários, coberturas lateríticas e depósitos aluviais.

A configuração geomorfológica da área da APA Sul RMBH é caracterizada por um conjunto de relevos predominantemente montanhosos, intensamente orientados pelo contexto litoestrutural de uma singular unidade geotectônica: o Quadrilátero Ferrífero $(\mathrm{QFe})$.

Ocorrem as seguintes classes de solo: Argissolo Vermelho, Argissolo Vermelho-Amarelo, Cambissolo Háplico, Gleissolo Háplico, Latossolo Vermelho, Latossolo Vermelho-Amarelo, 
Neossolo Flúvico, Neossolo Litólico, Neossolo Regolítico e Plintossolo Pétrico além de terrenos onde ocorrem exposição de canga, afloramentos rochosos, áreas degradadas por mineração, escavação, ferrovia ou voçorocas.

O clima predominante na área da APA Sul RMBH é quente e temperado, com uma pluviosidade significativa ao longo do ano, alternando entre verão chuvoso e estação seca no inverno. De acordo com a classificação de Köppen e Geiger a classificação do clima é Cwa. De acordo com as normais climatológicas (INMET, 2009) temperatura média em Belo Horizonte é $21,1{ }^{\circ} \mathrm{C}$ e a precipitação acumulada é de 1463,7 mm anuais.

\section{MATERIAIS E MÉTODOS}

O desenvolvimento do trabalho ocorreu por meio de 3 etapas: (a) Definição das variáveis e processos trabalhados, (b) Download e organização da base de dados, e (c) Análise multicritério por meio do método Análise hierárquica de Processos - AHP. A figura 2 abaixo mostra as etapas de desenvolvimento.

Figura 2 - Fluxos de realização do estudo

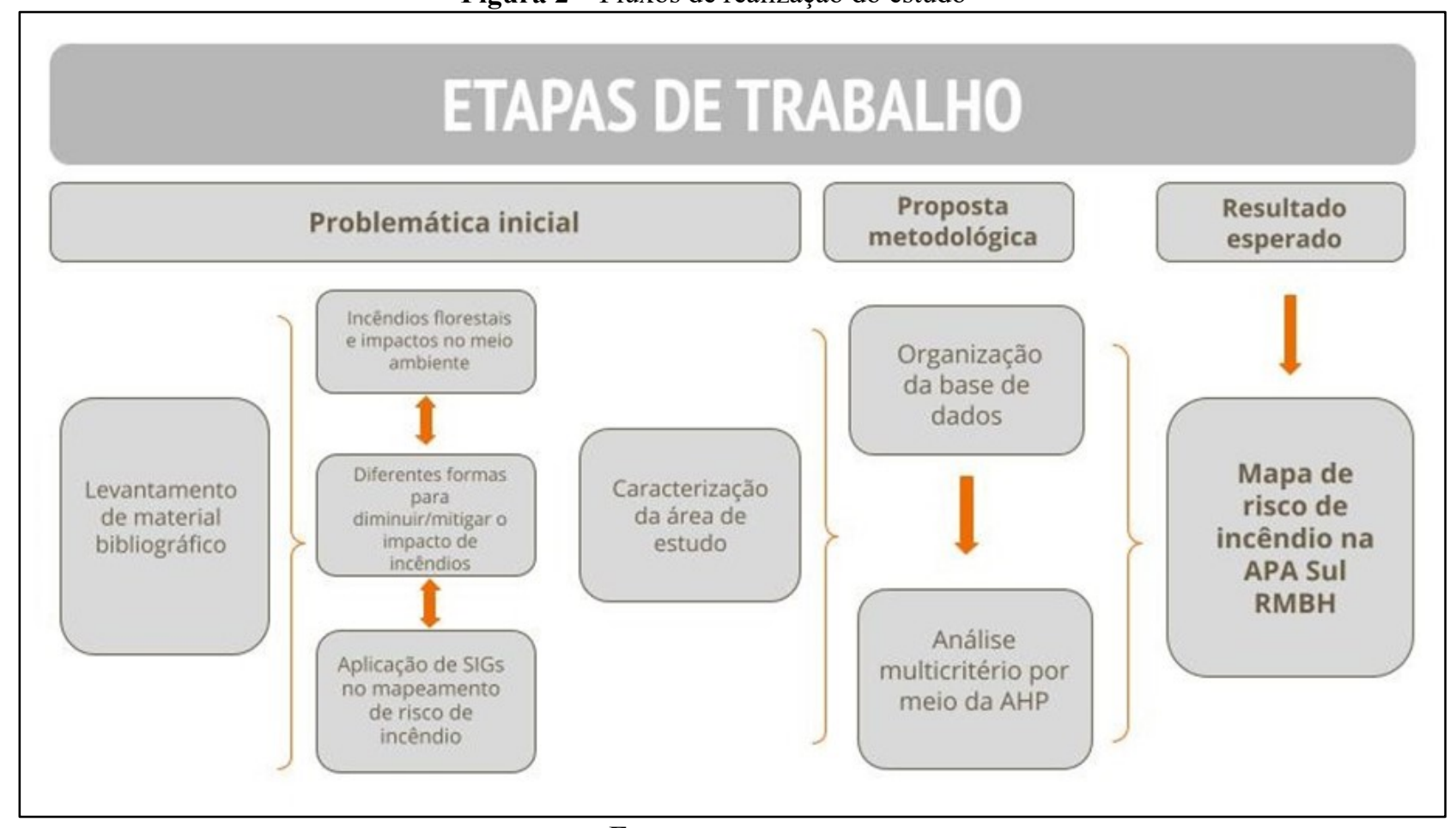

Fonte: os autores

\subsection{Tratamento e consolidação da base de dados}

A base de dados foi constituída a partir de parâmetros previamente selecionados, considerando as características físicas e socioespaciais da APA SUL elencadas como fatores que 
interferem e/ou podem interferir na ocorrência de incêndio, definidos por meio da revisão bibliográfica realizada (tabela 2).

Tabela 2 - bases cartográficas utilizadas no estudo

\begin{tabular}{c|c|c|c|c}
\hline Camada & Fonte de produção & Fonte de obtenção & Formato & Escala \\
\hline Limite da APA Sul RMBH & IEF, 2014 & IDE-Sisema & Vetorial & $1: 50.000$ \\
Altimetria & ASF, 2021 & ASF & Matricial & $12 \mathrm{~m}$ (resolução esp.) \\
Uso do solo & Mapbiomas, 2019 & Mapbiomas & Vetorial & $1: 100.000$ \\
Rede rodoviária & IBGE, 2019 & IBGE & Vetorial & $1: 250.000$ \\
Rede ferroviária & IBGE, 2019 & IBGE & Vetorial & $1: 250.000$ \\
Sedes municipais & IEDE, 2020 & IEDE & Vetorial & $1: 50.000$ \\
Aglomerados rurais & IBGE, 2019 & IBGE & Vetorial & $1: 250.000$ \\
Normais Climatológicas & INMET, 2010 & INMET & Alfanumérico & $1: 250.000$ \\
Focos de calor & INPE, 2020 & INPE & Vetorial & $1: 100.000$ \\
\hline
\end{tabular}

Fonte: os autores

Os dados foram configurados em sistema de coordenadas planas, projeção UTM Fuso 23 Sul e Datum SIRGAS 2000. Foi utilizado, para processamento dos dados, o software ArcGIS, em sua versão 10.6, sob licença estudantil adquirida. A partir do modelo digital de elevação (MDE), base de altimetria, foi possível produzir dados de declividade, calculada em porcentagem, e orientação do relevo. Através da base alfanumérica das Normais Climatológicas realizou-se processo de interpolação para criação de dados matriciais de temperatura e precipitação na APA Sul. Foi calculada a distância euclidiana para as bases de rodovias, ferrovias e localidades, de modo a se estimar dados métricos desses a todo o recorte de estudo. Em todos os processos descritos utilizou-se as ferramentas Slope, para geração de declividades; aspect, para orientação do relevo; e IDW, para interpolação dos dados climáticos, sendo todas ferramentas do pacote Spatial Analyst. Para realização da modelagem das variáveis, foi feita categorização das variáveis em classes, conforme interpretação com base nas características dos dados, bem como através da revisão bibliográfica feita (figura 3).

Para a variável de Uso do Solo, considerou-se cada classe de uso do mapeamento. A variável de Orientação do Relevo foi categorizada com base nos ângulos de cada direção cardeal e colateral apresentadas na base. Na variável declividade foi considerado os critérios de Fases de Relevo proposto por Santos (2018), que considera condições de declividade e relevo associadas as formas topográficas existentes. Para dados de altimetria, precipitação e temperatura definiu-se intervalos correspondentes as "quebras naturais" de distribuição dos dados, que melhor se adaptaram as condições naturais de dispersão espacial. Por fim, os dados de distância a rodoferrovias e localidades foram categorizados em intervalos de distância elaborados com base na proposta de Vetorrazzi (2006), de incidência a fragilidades e risco. 
Figura 3 - Variáveis analisadas no estudo

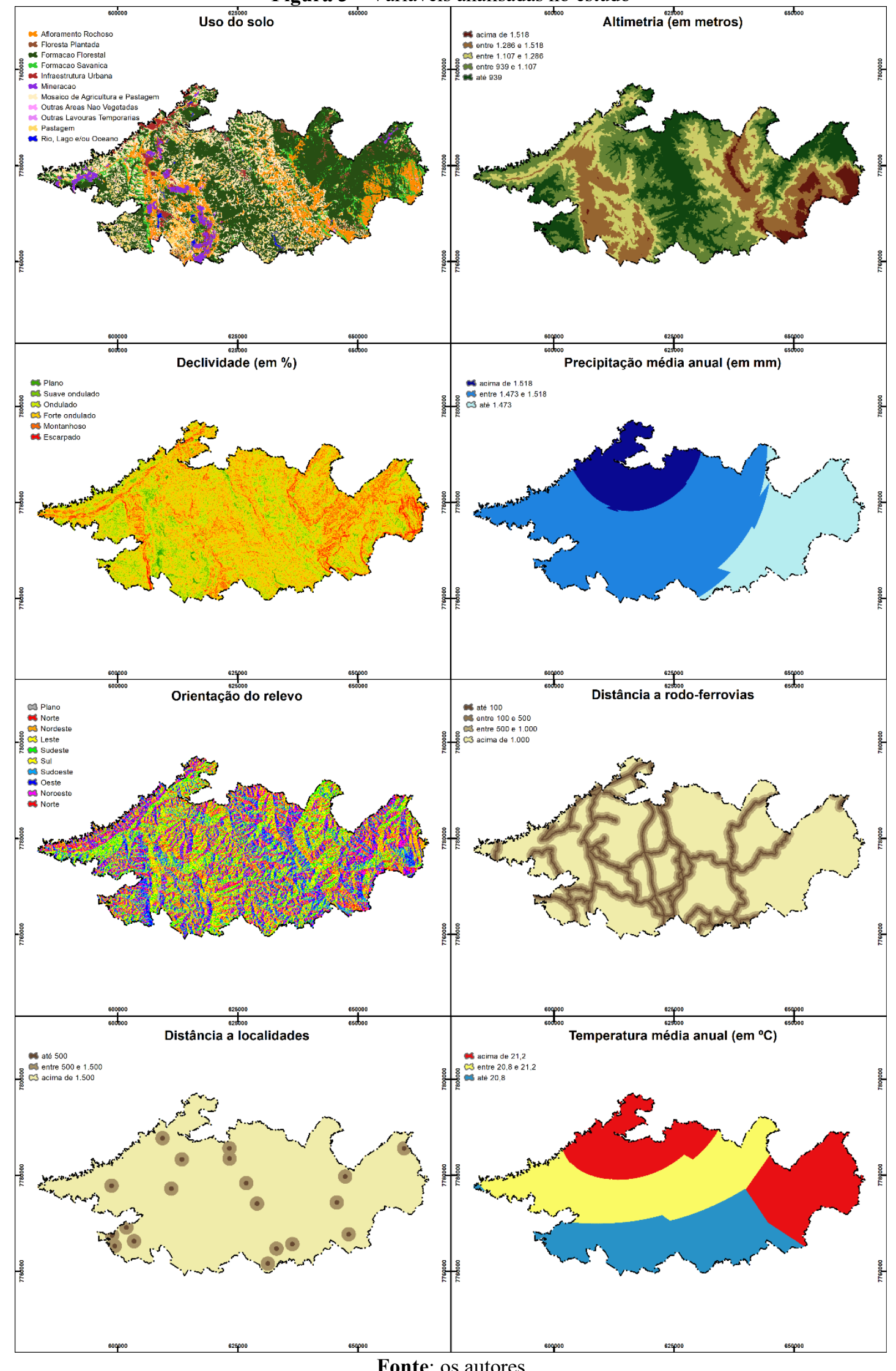

Fonte: os autores 


\subsection{Modelagem dos dados pelo método AHP}

A avaliação multicritério ocorreu por meio da Análise Hierárquica de Processos, proposta por Saaty (1980). As variáveis utilizadas, descritas acima, foram ponderadas tendo como base a revisão bibliográfica. O processo de avaliação de importâncias e pesos, tanto das classes quanto das variáveis em análise, seguiu o modelo de escala de prioridades proposto por Saaty (1980), em uma variação entre classes e variáveis que menos contribuem para o processo estudado as variáveis que possuem contribuição significativa e/ou absoluta (figura 4).

Figura 4 - Escala de análise pareada do método AHP

\begin{tabular}{|c|c|c|c|c|c|c|c|c|}
\hline $1 / 9$ & $1 / 7$ & $1 / 5$ & $1 / 3$ & 1 & 3 & 5 & 7 & 9 \\
\hline $\begin{array}{c}\text { Extrema- } \\
\text { mente }\end{array}$ & $\begin{array}{c}\text { Muito } \\
\text { fortemente }\end{array}$ & Fortemente & $\begin{array}{c}\text { Moderada- } \\
\text { mente }\end{array}$ & Igualmente & $\begin{array}{c}\text { Moderada- } \\
\text { mente }\end{array}$ & Fortemente & $\begin{array}{c}\text { Muito } \\
\text { fortemente }\end{array}$ & $\begin{array}{c}\text { Extrema- } \\
\text { mente }\end{array}$ \\
\hline
\end{tabular}

Menos Importante

Mais Importante

Fonte: Saaty (1980)

Como resultado, obteve-se as notas e pesos necessários para realização do processo de cruzamento dos dados através da álgebra de mapas (tabela 3 ).

Tabela 3 - Notas e pesos atribuídos as variáveis analisadas no estudo

\begin{tabular}{|c|c|c|c|}
\hline Variável & Categorias & Nota das classes & Peso das variáveis \\
\hline Declividade & $\begin{array}{c}\text { Plano (0 a } 3 \%) \\
\text { Suave ondulado (3 a } 8 \%) \\
\text { Ondulado (8 a } 20 \%) \\
\text { Forte ondulado }(20 \text { a } 45 \%) \\
\text { Montanhoso }(45 \text { a } 75 \%) \\
\text { Escarpado (acima de } 75 \%)\end{array}$ & $\begin{array}{l}5 \\
7 \\
7 \\
5 \\
3 \\
1\end{array}$ & $17 \%$ \\
\hline Orientação do relevo & $\begin{array}{c}\text { Plano }\left(-1^{\circ}\right) \\
\text { Norte }\left(-1 \text { a } 22,5^{\circ}\right) \\
\text { Nordeste }\left(22,5 \text { a } 67,5^{\circ}\right) \\
\text { Leste }\left(67,5 \text { a } 112,5^{\circ}\right) \\
\text { Sudeste }\left(112,5 \text { a } 157,5^{\circ}\right) \\
\text { Sul }\left(157,5 \text { a } 202,5^{\circ}\right) \\
\text { Sudoeste }\left(202,5 \text { a } 247,5^{\circ}\right) \\
\text { Oeste }\left(247,5 \text { a } 292,5^{\circ}\right) \\
\text { Noroeste }\left(292,5 \text { a } 337,5^{\circ}\right) \\
\text { Norte }\left(337,5 \text { a } 359,7^{\circ}\right)\end{array}$ & $\begin{array}{l}1 \\
7 \\
7 \\
5 \\
1 \\
1 \\
1 \\
5 \\
7 \\
7\end{array}$ & $5 \%$ \\
\hline Altimetria & $\begin{array}{l}\text { entre } 705 \text { e } 939 \text { metros } \\
\text { entre } 940 \text { e } 1.107 \text { metros } \\
\text { entre } 1.107 \text { e } 1.286 \text { metros } \\
\text { entre } 1.286 \text { e } 1.518 \text { metros } \\
\text { acima de } 1.518 \text { metros }\end{array}$ & $\begin{array}{l}7 \\
5 \\
5 \\
3 \\
1\end{array}$ & $7 \%$ \\
\hline
\end{tabular}




\begin{tabular}{|c|c|c|c|}
\hline Uso do solo & $\begin{array}{c}\text { Afloramento rochoso } \\
\text { Floresta plantada } \\
\text { Formação florestal } \\
\text { Formação savânica } \\
\text { Infraestrutura urbana } \\
\text { Mineração } \\
\text { Mosaico de agricultura e pastagem } \\
\text { Outras áreas não vegetadas } \\
\text { Pastagem } \\
\text { Outras lavouras temporárias }\end{array}$ & $\begin{array}{l}1 \\
7 \\
5 \\
5 \\
1 \\
3 \\
7 \\
5 \\
7 \\
7\end{array}$ & $23 \%$ \\
\hline Temperatura & $\begin{array}{c}\text { até } 20,88^{\circ} \mathrm{C} \\
\text { entre } 20,88 \text { e } 21,2^{\circ} \mathrm{C} \\
\text { acima de } 21,2^{\circ} \mathrm{C}\end{array}$ & $\begin{array}{l}3 \\
5 \\
7\end{array}$ & $7 \%$ \\
\hline Precipitação & $\begin{array}{c}\text { até } 1488 \mathrm{~mm} \\
\text { entre } 1488 \text { e } 1532 \mathrm{~mm} \\
\text { acima de } 1532 \mathrm{~mm}\end{array}$ & $\begin{array}{l}7 \\
5 \\
1\end{array}$ & $8 \%$ \\
\hline Distância a rodoferrovias & $\begin{array}{l}\text { até } 100 \text { metros } \\
\text { entre } 100 \text { e } 500 \text { metros } \\
\text { entre } 500 \text { e } 1.000 \text { metros } \\
\text { acima de } 1.000 \text { metros }\end{array}$ & $\begin{array}{l}7 \\
5 \\
3 \\
1\end{array}$ & $22 \%$ \\
\hline Distância a localidades & $\begin{array}{l}\text { até } 500 \text { metros } \\
\text { entre } 500 \text { e } 1.000 \text { metros } \\
\text { acima de } 1.000 \text { metros }\end{array}$ & $\begin{array}{l}7 \\
5 \\
1\end{array}$ & $11 \%$ \\
\hline
\end{tabular}

Fonte: os autores

O Índice de Consistência (IC) da matriz ponderada, proposto por Saaty (1980) como forma de avaliação da acurácia da análise pareada, foi de 0,0043 , estando dentro do valor máximo para consistência da análise, de 0,1 .

\section{RESULTADOS E DISCUSSÃO}

Considerando o quantitativo espacial de áreas por nível de risco de incêndios (tabela 4), verificou-se o predomínio de áreas risco médio e baixo que, juntos, ocuparam $78 \%$ da área total da APA Sul. Áreas de alto risco corresponderam a um segundo nível de ocupação, intermediário, enquanto que as classes extremas - muito baixo e muito alto - obtiveram os menores quantitativos. Áreas de risco muito alto, ademais, responderam por menos de $1 \%$ da área total da APA Sul.

Tabela 4 - Estatísticas zonais das áreas de risco de incêndio na APA Sul RMBH

\begin{tabular}{c|c|c}
\hline $\begin{array}{c}\text { Nível de } \\
\text { risco }\end{array}$ & $\begin{array}{c}\text { Área ocupada (em } \\
\text { hectares) }\end{array}$ & $\begin{array}{c}\text { \% da área } \\
\text { total }\end{array}$ \\
\hline Muito alto & 49,0 & 0,1 \\
\hline Alto & $23.634,2$ & 14,5 \\
\hline Médio & $67.610,0$ & 41,5 \\
\hline Baixo & $59.452,6$ & 36,5 \\
\hline Muito baixo & $12.113,6$ & 7,4 \\
\hline TOTAL & $\mathbf{1 6 2 . 8 5 9 , 4}$ & $\mathbf{1 0 0 , 0}$
\end{tabular}


E como produto cartográfico subsequente, obteve-se o mapa de risco de incêndios na APA sul da RMBH (figura 5).

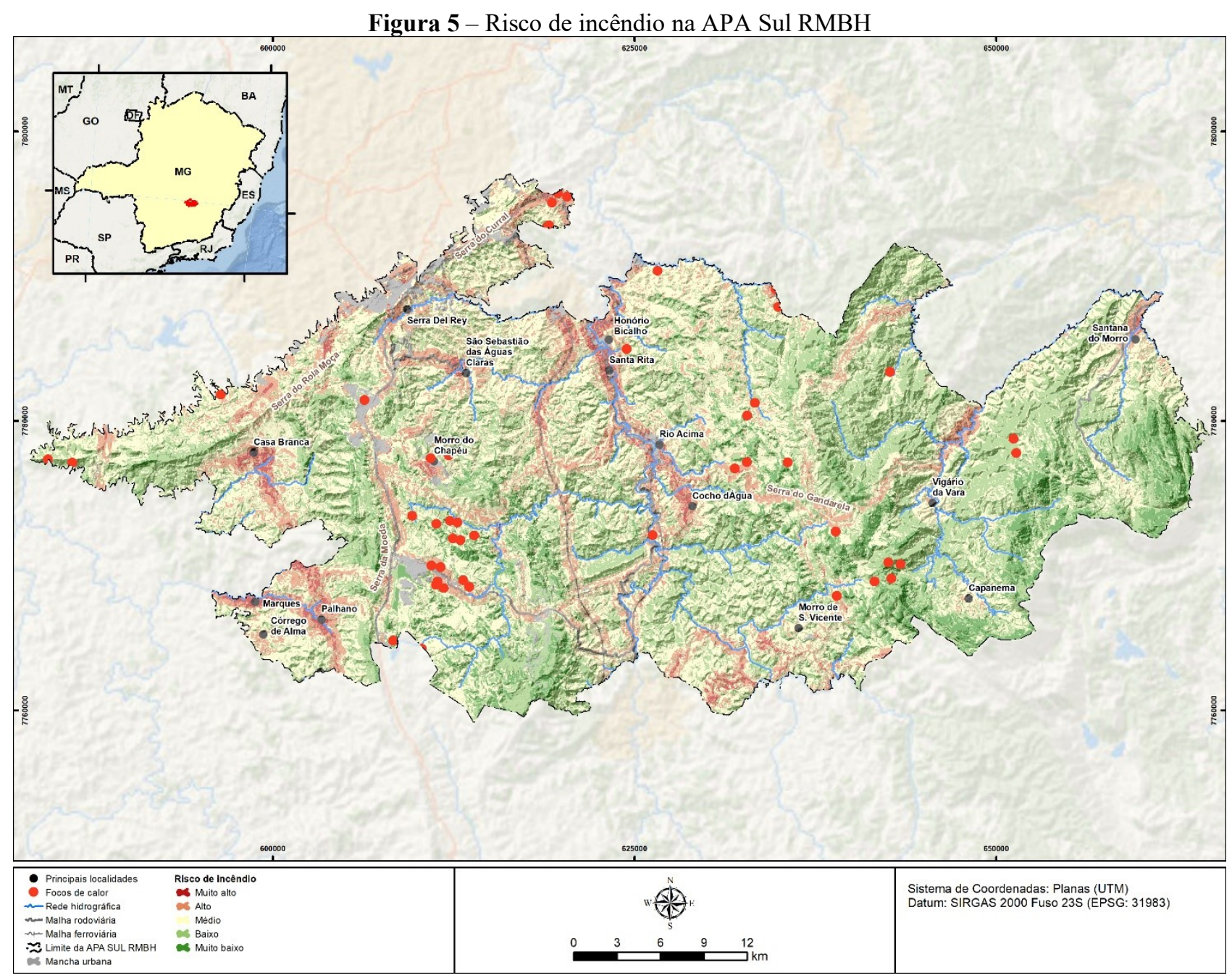

Fonte: os autores

As áreas de risco muito alto, $0,1 \%$ do somatório total, restringiram-se a pequenas porções localizadas em locais de temperatura superior a classe máxima, de $21,2^{\circ} \mathrm{C}$ e precipitação acima de $1487 \mathrm{~mm}$, considerando as normais climatológicas registradas. A altitude média verificada esteve dentro da classe mais baixa do relevo da APA Sul, com valores entre 705 e 940 metros. O nível de declividade nas áreas de alto risco variou entre 0 e 20\%, classes características de relevos planos, suave ondulado e ondulados. A orientação do relevo apresentada em tal classe predominou para nordeste e leste. O uso do solo predominante foi o de pastagens e pastagens com mosaicos de agricultura. Os raios de até 500 metros de distância de localidades e rodo-ferrovias concentraram a localização das áreas de risco muito alto, denotando a proximidade a tais equipamentos e/ou infraestruturas, ainda que, considerando a análise em relação ao uso do solo, não houve presença de áreas sobrepostas a áreas urbanas. Não foi registrado nenhum foco de calor registrado em 2020 com as áreas de risco muito alto. 
As áreas de risco alto, $1,8 \%$ da área total da APA Sul, foram predominantes em locais onde o uso do solo é composto por pastagens, mosaicos de agricultura e formação florestal. Menos de $1 \%$ das áreas de alto e muito alto risco ocorreram em usos correspondentes a ocupação urbana. Os níveis de declividade para tais classes variaram entre 3 e 20\% de inclinação, característicos de relevos suave ondulados a ondulados. A predominância de alto e muito alto risco em orientações de relevo se deu para nordeste, leste e noroeste, além de ocorrer em áreas cuja altimetria se situou entre 705 e 939 metros, áreas mais baixas da APA. Quando considerado a distribuição ao longo das faixas de distância a rodo-ferrovias e localidades, demonstrou-se concentração nas distâncias de até 500 metros, junto a presença de polígonos menores e mais dispersos ao longo dos limites superiores a 1000 metros. Padrão semelhante foi verificado com a distância a partir de localidades. Quando considerado os dados de precipitação e temperatura, verificou-se certo padrão de concentração entre níveis de 1487 e $1532 \mathrm{~mm}$, para precipitação, e acima de $20,8^{\circ} \mathrm{C}$, para temperatura. Foram verificados 6 pontos de concentração de calor dentro das áreas de alto risco de incêndio.

Representando mais da metade da área total da APA Sul - cerca de 54,2\% - as áreas de risco médio apresentam padrão de distribuição por todas as características ambientais e sócio espaciais analisadas. Cabe destacar a presença de 22 dos 48 focos de calor mapeados em 2020, indicando possível não evolução de tais pontos a locais de incêndio.

$\mathrm{Na}$ classe de baixo risco, foi observada sua localização em áreas com declividade superior a $20 \%$ de inclinação, especialmente em áreas entre 45 e $75 \%$, locais de relevo forte ondulado e montanhoso, respectivamente. As orientações de relevo a sul, sudoeste e sudeste foram as que mais concentraram o nível supracitado. O padrão de altitude apresentado variou entre 940 e 1.500 metros, sendo as serras da Moeda e do Gandarela os locais com maior presença de locais de baixo risco. As áreas de formação florestal e afloramento rochoso foram as principais classes de uso e ocupação do solo recorrentes. Quando considera as distâncias a partir de rodo-ferrovias e localidades, apresentouse concentração dos níveis de baixo risco nas faixas acima de 1.000 metros de distância de ambos, e, em menor escala, a partir de 500 metros. Houve padrão de distribuição equilibrado para todas as classes de temperatura e precipitação, indicando dispersão dos níveis de baixo risco em tais variáveis. Foram identificados 13 pontos de focos de calor dentro da classe analisada.

Cerca de $80 \%$ das áreas de risco muito baixo localizaram-se em regiões com declividade superior a $45 \%$, em relevos fortemente ondulados e montanhosos. Outros 8,8\% em declividades onduladas (entre 20 e 45\%) e 6\% em declividades escarpadas (acima de 75\%). Consequentemente, a predominância altimétrica ocorreu em cotas acima de 1250 metros, alcançando os valores máximos registrados na APA - de 2.074 metros. Ambas as principais serras do local - Moeda e Gandarela apresentaram padrão de risco variando do baixo ao muito baixo. $\mathrm{Na}$ análise com base no uso do solo, verificou-se predominância de $90 \%$ sobre áreas de afloramento rochoso, sendo o restante disperso em 
áreas de mineração. A distribuição espacial sobre as faixas de distância em relação a localidades e rodo-ferrovias foi majoritária nas faixas acima de 1.000 metros. Sobre as características de precipitação e temperatura, constata-se concentração em faixas abaixo de $1500 \mathrm{~mm} \mathrm{e} 21^{\circ} \mathrm{C}$, respectivamente. Foram identificados 3 focos de calor dentro da classe muito baixa de risco.

\section{CONSIDERAÇÕES FINAIS}

A análise através da AHP demonstrou alta eficácia, no que tange a consistência das ponderações, demonstrado pelo índice de consistência. As ponderações direcionaram-se a fatores que possuem significativo impacto na propagação e controle do fogo, considerando a revisão bibliográfica realizada, como o uso do solo, a proximidade a infraestruturas como rodovias e ferrovias e o grau de declividade das formas de relevo.

Entre as potencialidades do estudo, pode-se elencar a alta correlação entre as áreas com alto risco de incêndio e as classes definidas, indicando correspondência com a realidade espacial da APA Sul, além da possibilidade de utilização dos produtos obtidos - tanto as ponderações realizadas quanto o mapa elaborado - como instrumento de análise em planos de manejo e como comparativo - ou suporte - em zoneamentos ambientais e ecológico-econômicos.

Como limitações encontradas, destaca-se a escala de dado de algumas variáveis, como as de temperatura e precipitação, onde a existência de poucas estações meteorológicas impediu um mapeamento mais preciso sobre as condições climáticas específicas da APA Sul, limitando o estudo a uma caracterização regional, no que toca ao fator climático.

Citam-se como recomendações a produção de dados em casos de limitação de escala - como visto na temperatura e na precipitação, para aperfeiçoar o estudo. Além disso, a utilização de outros métodos de análise multicritério - como o modelo Delphi - onde haja a avaliação direta por especialistas, bem como o uso do estudo como base para análise de fragilidade ambiental, tendo como referencial metodologias de cálculo de tal fator no recorte estudado.

\section{REFERÊNCIAS}

ALASKA SATELITE FACILITY (ASF). Data Search Vertex. United States, 2021. Disponível em: https://search.asf.alaska.edu/. Acesso em: 15/03/2021.

FERNANDES, L. C.; NERO, M. A.; TEMBA, P. da C.; ELMIRO, M. A. T. The use of remote sensing techniques by Modis (MCD45A1) images using to identify and evaluate burned areas in the metropolitan region of Belo Horizonte - MG, Brazil. Sustentabilidade em Debate, [S. 1.], v. 11, n. 2, p. 143-172, 2020. DOI: 10.18472/SustDeb.v11n2.2020.28145. Disponível em: https://periodicos.unb.br/index.php/sust/article/view/28145. Acesso em: 31/03/2021.

INSTITUTO BRASILEIRO DE GEOGRAFIA E ESTATÍSTICA (IBGE). Base Cartográfica Contínua do Brasil - 1:250.000. Rio de Janeiro, 2019, $4^{\mathrm{a}}$ versão. Disponível 
em:https://geoftp.ibge.gov.br/cartas_e_mapas/bases_cartograficas_continuas/bc250/versao2019/. Acesso em: 15/03/2021.

INSTITUTO ESTADUAL DE FLORESTAS (IEF). Base de Dados Geoespaciais de Unidades de Conservação. Belo Horizonte, 2014. Disponível em: http://www.ief.mg.gov.br/component/content/article/3306-nova-categoria/2073-banco-de-dados-deucs-estaduais. Acesso em: 15/03/2021.

INSTITUTO NACIONAL DE METEOROLOGIA (INMET). Normais Climatológicas do Brasil, 1961-1990. Brasília - DF. 2009. Disponível em: http://www.inmet.gov.br/portal/index.php?r=clima/normaisclimatologicas. Acesso em: 15/03/2021.

INSTITUTO NACIONAL DE METEOROLOGIA (INMET). Dados Históricos Anuais das Estações Automáticas. Disponível em: https://portal.inmet.gov.br/dadoshistoricos. Acesso em: $15 / 03 / 2021$.

INSTITUTO NACIONAL DE PESQUISAS ESPACIAIS (INPE). Banco de Dados de Queimadas. Brasil, 2021. Disponível em: http://queimadas.dgi.inpe.br/queimadas/bdqueimadas/. Acessado em: $15 / 03 / 2021$.

InStituto socioambiental (ISA). Área de Proteção Ambiental Sul RMBH. Disponível em: https://uc.socioambiental.org/pt-br/arp/2430. Acesso em: 15/03/2021.

LAZZARINI, G.; FERREIRA, L.; FELICÍSSIMO, M.; OLIVEIRA, L. \& GIONGO, M. Análise da Detecção e Ocorrência de Queimadas em Áreas Urbanizadas e Entorno. Ciência e Natura, v. 38, n.3, p. 1265-1275, 2016. DOI: https://doi.org/10.5902/2179460X21536. Disponível em: https://periodicos.ufsm.br/cienciaenatura/article/view/21536/pdf. Acesso em 31/03/2021.

NERY, Flávio Henrique. Identificação das Áreas Potenciais para a Ocorrência de Incêndios Florestais no Parque Nacional da Serra da Canastra. 2011. 38 f. Monografia (Especialização em Geoprocessamento) - Instituto de Geociências, Universidade Federal de Minas Gerais, Belo Horizonte, 2011.

OLIVEIRA, Graziela da Silva Rocha; JACQUES, Patrícia Duringer; SHINZATO, Edgar. Projeto APA Sul RMBH: Estudos do Meio Físico, Escala 1:50.000. Belo Horizonte: CPRM/Embrapa/SEMAD/Cemig. 2005.

SAATY, Thomas L. The Analytic Hierarchic Process: Planning Setting Priorities, Resource Allocation. New York: McGraw-Hill, 1980.

SANTOS, H.G. dos; JACOMINE, P.K.T.; ANJOS, L.H.C. dos; OLIVEIRA, V.A. de; OLIVEIRA, J.B. de; COELHO, M.R.; LUMBRERAS, J.F.; CUNHA, T.J.F. (Ed.). Sistema brasileiro de classificação de solos. 2.ed. Brasília: Embrapa Solos, 2018. 356p.

SILVA, Adélia Alves de Lima. O Uso do Geoprocessamento no Mapeamento e Identificação de Áreas de Risco de Incêndio Florestais, com ênfase na região do Parque Estadual do Itacolomi, Ouro Preto / MG. 2004. 46 f. Monografia (Especialização em Geoprocessamento) - Instituto de Geociências, Universidade Federal de Minas Gerais, Belo Horizonte, 2004.

TORRES, Fillipe Tamiozzo Pereira. Relações entre fatores climáticos e ocorrências de Incêndios Florestais na cidade de Juiz de Fora (MG). Caminhos de Geografia, Uberlândia, vol. 7, fasc. 18, p. 162-171, 2006/jun. 
TORRES, Fillipe Tamiozzo Pereira et al Mapeamento do Risco de Incêndios Florestais Utilizando Técnicas de Geoprocessamento. Floresta Ambient., Seropédica , v. 24, e00025615, 2017. DOI: http://dx.doi.org/10.1590/2179-8087.025615. Disponível em: http://www.scielo.br/scielo.php?script=sci_arttext\&pid=S2179-

80872017000100121\&lng=en\&nrm=iso. Acesso em: 31/03/2021.

UNIVERSIDADE FEDERAL DE VIÇOSA; FUNDAÇÃO CENTRO TECNOLÓGICO DE MINAS GERAIS; UNIVERSIDADE FEDERAL DE LAVRAS; FUNDAÇÃO ESTADUAL DO MEIO AMBIENTE. Mapa de solos do Estado de Minas Gerais. Belo Horizonte: Fundação Estadual do Meio Ambiente, 2010.

VETTORAZZI, Carlos Alberto. Avaliação Multicritérios, em ambiente SIG, na definição de áreas prioritárias à restauração florestal, visando à conservação de recursos hídricos. 2006. 151 p. Tese, (Livre-docência em Topografia) - Departamento de Engenharia Rural, Universidade de São Paulo, Piracicaba, 2006.

Trabalho enviado em 19/05/21

Trabalho aceito em 30/06/21 